\title{
Molecular Detection of Peste des-petits Ruminant Virus (PPRV) by RT-PCR
}

\author{
Pragati Bhoyar, Prabhakar Tembhurne*, Ruchi Bhate, Prashant Tarale, \\ Anuradha Nemade Anand Kadam, Jivan Kesharkar and V.C. Ingle \\ Department of Veterinary Microbiology and Animal Biotechnology, Nagpur Veterinary \\ College, Nagpur, India \\ *Corresponding author
}

\section{A B S T R A C T}

Keywords

PPRV, RT-PCR, PBMC, Nasal Swab

Article Info

Accepted:

30 October 2019

Available Online:

10 November 2019
Peste des petits ruminants is one of the important transboundary, highly contagious and infectious viral disease of small ruminants especially sheep and goats caused by Small Ruminant Morbillivirus alias Peste-des-petits ruminants virus. In the current study, PPRV was detected in clinical samples of suspected goats as well as post vaccinated samples in nasal swabs and PBMC by conventional RT-PCR. Out of the 23 nasal swabs (12 infected and 11 vaccinated) 11 infected and one vaccinated samples was found positive. Out of 16 (5 infected and 11 vaccinated), all five infected and one vaccinated PBMC samples were found positive. Thus, the present study delineated the presence of PPRV in clinical samples as well as viaremic stages of PPRV. Further sequencing and characterization will warrant lineage of PPRV circulating in Nagpur district of Maharashtra.

\section{Introduction}

Peste des petits ruminants is a distinguishable and economically important transboundary disease of sheep and goat. Peste des petits ruminants (PPR), is a highly contagious and infectious viral disease that led the high morbidity and mortality caused by Small Ruminant Morbilli Virus (SRMV) also known as Peste-des-petits ruminants virus (PPRV). SMRV is an enveloped, single-stranded negative-sense RNA virus, belonging to the genus morbillivirus within the family Paramyxoviridae along with other member including Rinderpest (Gibbs et al., 1979; ICTV report 2019). The PPRV disease exhibits clinical signs such as fever, oculonasal discharge, watery blood-stained diarrhea, dyspnea, sloughing of the epithelium of oral and nasal mucosa, which later becomes mucopurulent giving fetid odor. PPRV infection may end with high morbidity (up to $100 \%)$ and mortality of (80\%) and close contact between animals is highly risk factor 
to transmission of disease (Nanda et al., 1996; Dhar et al., 2002; Balamurugan et al., 2012; Truong et al., 2014). PPR has been reported in Africa, as well as in Middle East and Asia (Banyard et al., 2010). Many reports have been recorded in India since 1994 in southern and northern parts of India (Nanda et al., 1996). An outbreak of PPR was reported in Coimbatore, India in 2011, where the samples were investigated using RT-PCR targeting nucleocapsid (N), fusion (F) and haemagglutinin $(\mathrm{H})$ genes (Kumar et al., 2014).

The genome of PPRV contains, 3'-N-P-M-FH-L-5' which encodes for six structural proteins namely, nucleocapsid, phosphoprotein, matrix, fusion, haemagglutinin and large polymerase (Bailey et al., 2005; Nanda et al., 2006; Chard et al., 2008). The matrix protein ( $M$ protein) is located on the inner surface of the envelope which bridges the ribonulceoprotein and cytoplasmic tails of two membrane glycoprotein's, $\mathrm{H}$ and $\mathrm{F}$ proteins (Parida et al., 2015).

It is known to play a significant role in the virus assembly and budding by concentrating $\mathrm{F}$ and $\mathrm{H}$ proteins as well as ribonucleocapsid at virus assembly site. It may improve the growth characteristics of the virus, incorporating $\mathrm{M}$ protein. The diagnosis of PPRV is basically based on serological techniques and on viral isolation from clinically suspected samples.

These techniques are time- consuming, laborious and insensitive as well for PPRV detection (Libeau et al., 1994; CouacyHymann et al., 2002; Parida et al., 2015; Barrett et al., 1994; Singh et al., 2004). On the other hand, reverse transcription polymerase chain reaction (RT-PCR) considered as a diagnostic tool for PPR detection (Toplu et al., 2012). The present study was conducted to confirm the PPRV circulating in the Nagpur district as well as to ascertain the viaremic stages in the disease conditions or post vaccination using RT-PCR targeting M gene.

\section{Materials and Methods}

\section{Sample collection}

A total of 39 samples (nasal swab and blood) were collected from goats suspected for PPR disease, PPR vaccinated from different locations at Aptur village Umred Tahsil Dist. Nagpur and Nagpur city in year 2018-19 as detailed in table 1.

\section{Isolation of PBMC from blood}

Five milliliter blood was collected in the sterile vacutainer with pretreated anticoagulant from PPRV suspected infected, PPRV vaccinated goats. PBMC were isolated using Histopaque-1077 (Sigma) by density gradient centrifugation according to manufacturer's protocol. Briefly, the blood was diluted with sterile cell culture grade PBS in equal proportion. Histopaque reagent $(3 \mathrm{ml})$ was loaded on to $9 \mathrm{ml}$ of the diluted blood sample in a ratio of 1:3 which was then centrifuged at $2000 \mathrm{~g}$ for 25 minutes at room temperature. Various components in the blood could be seen as separate layers with plasma at top followed by a buffy coat of monocytes, histopaque and lymphocytes in the middle and RBC's at bottom. The buffy coat was collected carefully without disturbing any another component. The cells were then washed using $10 \mathrm{ml}$ isotonic phosphate buffer and centrifuged at $2000 \mathrm{~g}$ for 10 minute at room temperature. The pellet was obtain and resuspended in RNA later and stored in $-70{ }^{\circ} \mathrm{C}$.

\section{Isolation of RNA}

RNA isolation from PBMC was done by miRCURY ${ }^{\mathrm{TM}}$ RNA Isolation kit (Exiqon) and 
RNA isolation from Nasal swab was done by TRI reagent (Cat \# 15596026, Invitrogen). The isolated RNA was quantified by Nanodrop (NP 1000, Thermo fisher Scientific, USA). The RNA was used for PPRV confirmation as well miRNA/mRNA analysis (data not shown).

\section{cDNA synthesis}

The cDNA synthesis was carried out as per SuperScript ${ }^{\circledR} \quad$ III First-Strand Synthesis System for RT-PCR kit (Invitrogen, USA Cat. No. 18080-051) according to manufacturer's instructions in $20 \mu \mathrm{l}$ reaction volume containing the following reagent in labeled microcentrifuge tubes. Briefly, $10 \mu 1$ of reaction I was prepared by adding upto $5 \mu \mathrm{g}$ of total RNA, $1 \mu \mathrm{l}$ of random hexamer primers, $1 \mu \mathrm{l}$ of $10 \mathrm{mM}$ dNTP mixture and DEPC water was make up to $10 \mu 1$ reaction volume. The prepared reaction mixture I was incubated at $65^{\circ} \mathrm{C}$ for minutes and then it was snap chilled on ice for at least 1minute. Reaction II of $10 \mu 1$ was prepared by adding $2 \mu \mathrm{l}$ of 10X RT buffer, $4 \mu \mathrm{l}$ of $25 \mathrm{mM}$ Magnesium chloride, $2 \mu 1$ of $0.1 \mathrm{M}$ DTT, $1 \mu \mathrm{l}$ of RNase Out $(40 \mathrm{U} /) \mu 1$ and $1 \mu l$ of Superscript III Reverse Transcriptase $(200 \mathrm{I} / \mu \mathrm{l})$. The reaction I \& II was mixed and briefly centrifuged and incubated in PCR thermo-cycler (Prima Trio, High-Media, India) at $25^{\circ} \mathrm{C}$ for $10 \mathrm{~min}, 50^{\circ} \mathrm{C}$ for $50 \mathrm{~min}$ and followed by $85^{\circ} \mathrm{C}$ for 5 minutes. The synthesized cDNA was used immediately/ stored at $-20^{\circ} \mathrm{C}$ until used.

\section{Amplification of $\mathrm{M}$ gene by RT- PCR}

Polymerase chain reaction for amplification of $\mathrm{M}$ gene from samples was carried out using published primers PPR-M-FOR 5'TGTGTACATGAGCATAACTAGATT

ATCA-3' and PPR-M-REV 5'ACTTTCAATTCTTAGTAGTGTAACCAA GATG-3' (Balamurugan et al., 2006). The reaction mixture $(25 \mu \mathrm{l})$ was prepared containing $12.5 \mu \mathrm{l}$ of $2 \mathrm{X}$ PCR master mix (Purigene), $1 \mu \mathrm{l}$ each of $10 \mathrm{pmol}$ of forward and reverse primers, $1 \mu 1$ of template and $9.5 \mu 1$ of nuclease free water. The reaction was carried out in PCR thermo-cycler (Prima Trio, High-Media, India) with cyclic conditions: initial denaturation at $95^{\circ} \mathrm{C}$ for 2 minutes followed by 35 cycles of denaturation at $95^{\circ} \mathrm{C}$ for 20 seconds, annealing at $56^{\circ} \mathrm{C}$ for 1 minute, extension at $72^{\circ} \mathrm{C}$ for 45 seconds, with a final extension at $72^{\circ} \mathrm{C}$ for 10 minutes. The PCR products were analyzed on $2 \%$ agarose gel with 50bp DNA ladder (GeneRuler 50 bp cat \# SM0372 Thermo fisher Scientific, USA) for expected amplicon size of $124 \mathrm{bp}$.

\section{Results and Discussion}

The clinical signs of PPR suspected animal exhibits off feed, high body temperature with approximately $105-106^{0} \mathrm{~F}$, coughing, semi solid/profuse diarrhea, mouth ulcers were observed which were typical symptoms of PPRV infection (Fig. 1), whereas, none of the vaccinated animals showed any symptoms. The clinical symptoms indicated suspected for PPR disease outbreaks in Nagpur district. In different parts of the world, variable percentage of mortality and morbidity involving PPRV in both sheep and goat populations have been reported. The status of PPR by serology sheep and goats in southern India with a prevalence of $41.35 \%$ and $34.91 \%$ respectively have been reported (Raghavendra et al., 2008). All the studies showed that the prevalence of the disease might have been attributed due to agroclimatic conditions, socioeconomic factors and the pattern of migration of small ruminants in relation to season, flock size and population density of the animals.

A total of 39 samples (23 nasal swabs and 16 PBMC) were screened by $\mathrm{M}$ gene RT-PCR. Out of 39 samples, 12 nasal swabs and 16 PBMC were found to be positive. The 
expected $124 \mathrm{bp}$ amplicons was detected in nasal swabs and PBMC samples (Fig. 2A, 2B and Fig. 3).

In the present study, 11 infected samples out of 12 infected samples and one vaccinated out of 11 vaccinated nasal swab sample were found positive for the PPRV. The $124 \mathrm{bp}$ expected amplicons indicated the presence of PPRV in $91.66 \%$ positivity in PPR suspected goats whereas, $9.09 \%$ in nasal swabs of vaccinated goats. For the diagnosis of PPR several methods such as ELISA, conventional PCR were employed, however RT-PCR allows efficient virus detection in clinical samples such as nasal swabs (Forsyth and Barrett 1995; George et al., 2006; Bao et al., 2008). High sensitivity, specificity and rapidity of PCR makes it, the first choice of diagnostics in comparison to virus isolation, immune fluorescence. Since the detection of PPRV from clinical samples is difficult to assess by other diagnostic tools, RT-PCR is recognized as the most sensitive tool for the detection of viral products. The virus was readily detected in nasal swabs, makes it an optimal clinical sample from suspected animals for PPRV (Parida et al., 2019). Apart from nasal swabs, other samples can also have the potential for demonstrating the presence of virus in suspected samples. The detection was also done in PBMC isolated from blood. In the present study, 16 PBMC samples (5 infected and 11 vaccinated) were screened for PPRV, out of which 5 from infected and only one from the vaccinated was found positive for the PPRV. The PBMC samples from the suspected samples showed $100 \%$ positivity, however $9.09 \%$ in vaccinated samples. Studies have shown that PPRV could be detected from blood samples not only at late stages but also at early stage of infection. It was also showed that PPRV was successfully recovered from PBMC of sub clinically infected cattle (Sen et al., 2014). The present study delineated the presence of PPRV in clinical samples as well as viaremic stages of PPRV in clinical and post vaccinated sample. Further sequencing and characterization will warrant lineage of PPRV circulating in Nagpur district of Maharashtra. The study confirmed the circulation of PPRV in the different locality of Nagpur city and Umred tahsil, Nagpur district, Maharashtra. The trade of animals/ migration of animals, mixing of animals for market from different location might be responsible for regular outbreaks in Nagpur region of Maharashtra.

Table.1 Details of sample collection

\begin{tabular}{|c|c|c|}
\hline Place & Types of Samples & Number of Samples \\
\hline $\begin{array}{c}\text { Aptur village, Umred } \\
\text { Taluka, District. } \\
\text { Nagpur, Maharashtra }\end{array}$ & Nasal Samples & 4 (suspected for Infection) \\
\cline { 2 - 3 } & Blood Samples & $11(6-8$ days post Vaccination $)$ \\
\hline $\begin{array}{c}\text { Telankhedi, } \\
\text { Mominpura, Jafar } \\
\text { Nagar, Sadar Nagpur, } \\
\text { Maharashtra }\end{array}$ & Nasal Samples & 11 (6uspected for Infection) \\
\cline { 2 - 3 } & Blood Samples & 8 (suspected for Infection) \\
\hline & Total & 3 (suspected for Infection) \\
\hline
\end{tabular}


Fig.1 Clinical signs shown by PPRV infected animals
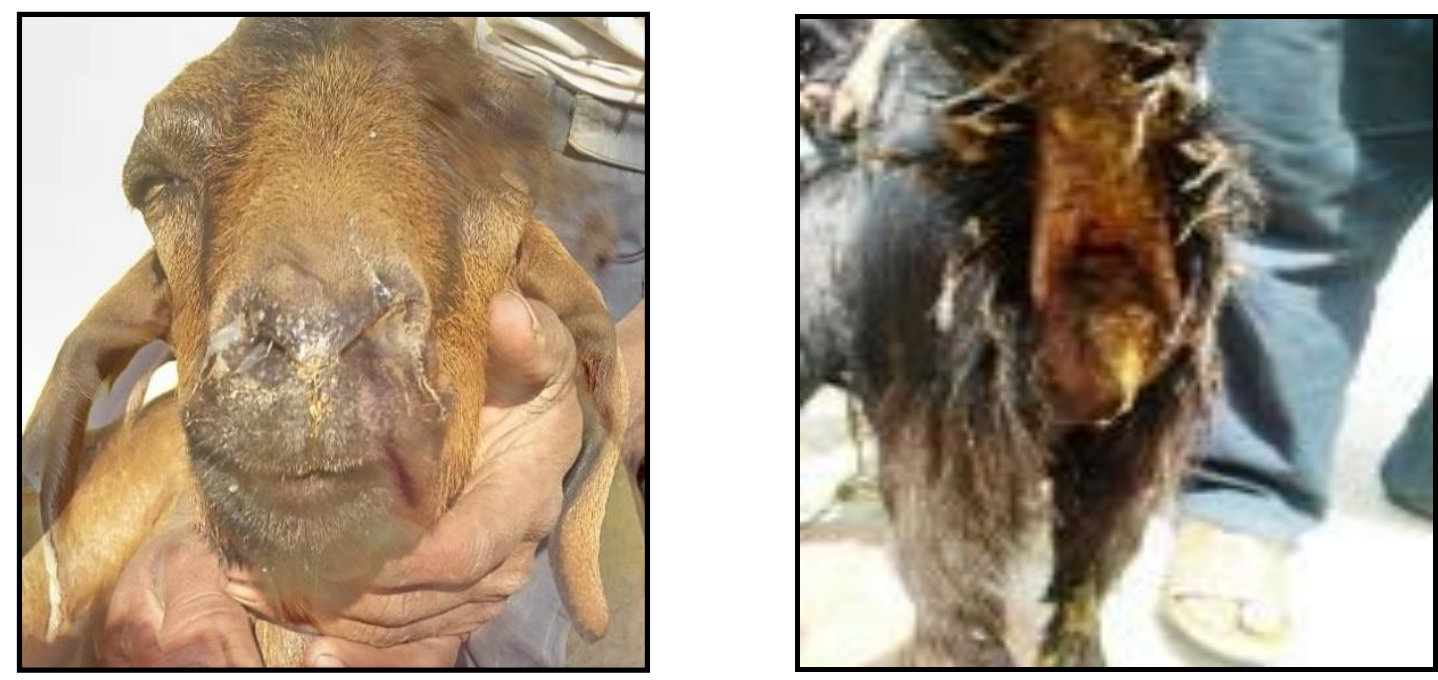

C. Showing ulcerative ulcers of mouth

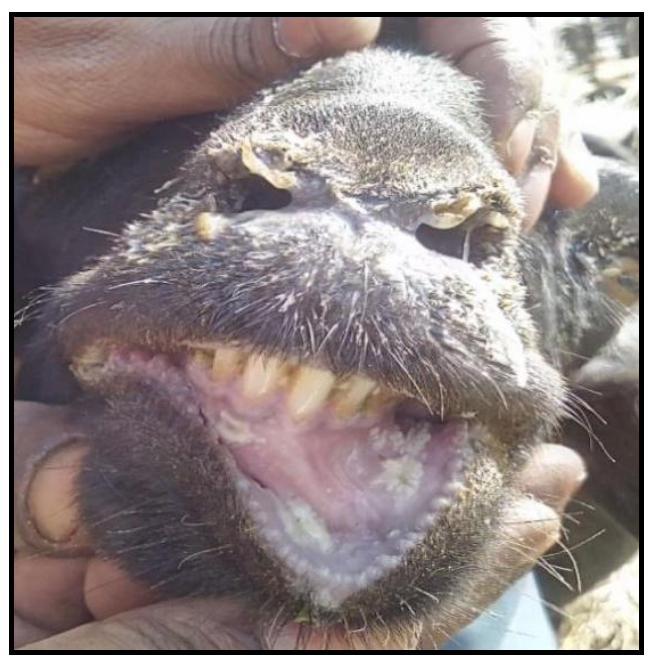

Fig.2






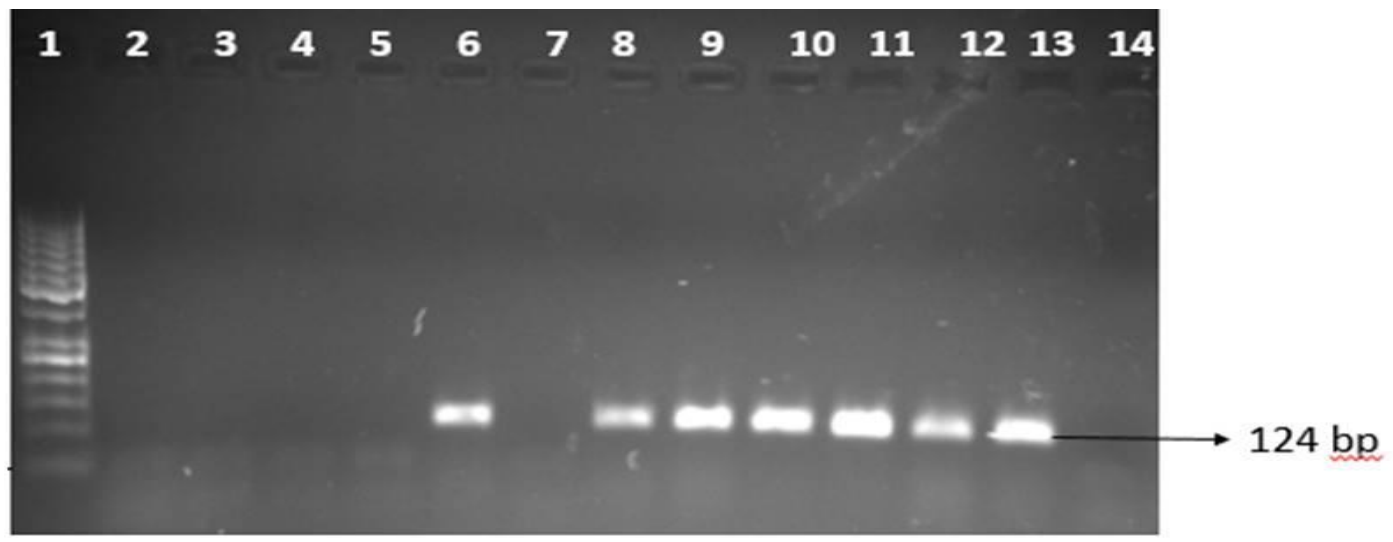

Figure 2.B: Agarose gel electrophoreis showing Mgene positive samples in nasal swabs with a product size of $124 \mathrm{bp}$

Lane 1: 50bp ladder

Lane2-12: Samples suspected for PPRV

Lane 13: Positive Control

Lane 14: Negative Control

Fig. 3

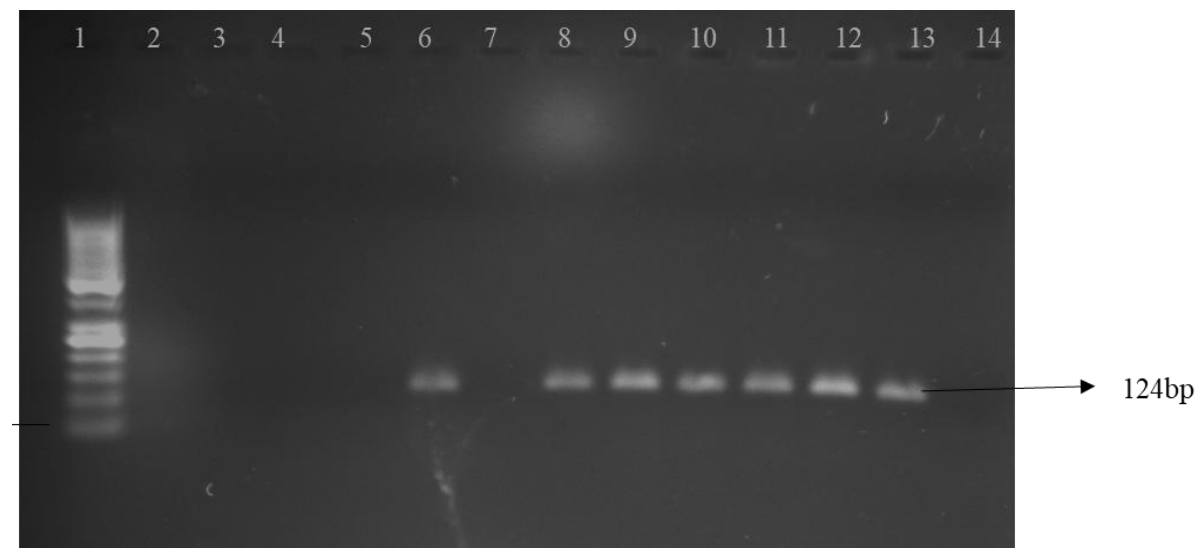

\section{Acknowledgement}

The authors acknowledge the financial support from the ICAR-NASF project (F. No. NASF/ABA-6021/2017-18) from Indian Council of Agricultural research, New Delhi and for infrastructural support from the Associate Dean, Nagpur Veterinary College, Nagpur.

\section{References}

Bailey, D., Banyard, A., Dash, P., Ozkul, A., and Barrett, T. 2005. Full genome sequence of peste des petits ruminants virus, a member of the Morbilli virus genus. Virus Res 110: 119-24.

Balamurugan, V., Krishamoorthy, P., Veeregowda, B., Sen, A., Rajak, K., Bhanuprakash, V., and Gajendragad, M. 2012. Seroprevalence of Peste des petits ruminants in cattle and buffaloes from Southern Peninsular India. 
Tropical Animal Health and production, 44: 301-306.

Balamurugan, V., Sen, A., Saravanan, P., Singh, R.P., Singh, R.K., Rasool, T.J., and Bandhyopadhyay, S. K. 2006. One-step multiplex RT-PCR assay for the detection of PPR virus in clinical samples. Vet. Res. Commun. 30: 655666.

Banyard, A. C., Parida, S., Batten, C., Oura, C., Kwiatek, O., and Libeau, G. 2010. Global distribution of peste des petits ruminants virus and prospects for improved diagnosis and control. J. Gen Virol. 91, 2885-2897.

Bao, J., Li, L., Wang, Z., Barrett, T., Suo, L., Zhao, W. Liu, Y., Liu, C., and Li, J. 2008. Development of one-step realtime RT-PCR assay for detection and quantitation of peste des petits ruminants virus. J. Virol. Methods 148: 232-236.

Barrett, T. 1999. Morbillivirus infections, with special emphasis on morbilli viruses of carnivores. Vet Microbiol. 69: 3-13.

Chard, L.S., Bailey, D.S., Dash, P., Banyard, A.C., and Barrett, T. 2008. Full genome sequences of two virulent strains of peste-des-petits ruminants virus, the Côte d'Ivoire1989 and Nigeria 1976 strains. Virus Res. 136: 192-7.

Couacy-Hymann, E., Roger, F., Hurard, C., Guillou, J.P., Libeau, G., and Diallo, A. 2002. Rapid and sensitive detection of peste des petits ruminants virus by a polymerase chain reaction assay. $\mathrm{J}$ Virol Methods, 100:17-25.

Dhar, P., Sreenivasa, B.P., Barrett, T., Carteun, M., Singh, R.P., and Bandyopadhyay, S. K. 2002. Recent epidemiology of Peste des petitis ruminant virus (PPRV). Vet Microbiol. 88: 153-159.

Forsyth, M.A., and Barrett, T. 1995. Detection and differentiation of rinderpest and Peste-des-petitsruminants viruses in diagnostic and experimental samples by polymerase chain reaction using $\mathrm{P}$ and $\mathrm{F}$ genespecific primers. Virus Res. 39: 151163.

George, A., Dhar, P., Sreenivasa, B.P., Singh, R.P., and Bandyopadhyay, S.K. 2006. The $\mathrm{M}$ and $\mathrm{N}$ genes-based simplex and multiplex PCRs are better than the F or $\mathrm{H}$ gene-based simplex PCR for Pestedes-petits-ruminants virus. Acta Virol. 50: 217-222.

Gibbs, E., Taylor, W., Lawman, M., and J. Bryant 1979. Classification of Peste des Pestits Ruminants Virus as the fourth member of the Genus Morbilivirus. Intervirology, 11: 268274.

ICTV Taxonomy history, small ruminants morbilivirus (htm). International Committee on Taxonomy of Viruses (ICTV) Retrieved (Jan) 2019.

Kumar, S.K., Babu, A., Sundarapandian, G., Roy, P., Thangavelu, A., Kumar, S.K., Arumugam, R., Chandran, N.D.J., Muniraju, Mahapatra, M., Banyard, A.C., Manohar, B.M., and Parida, S. 2014. Molecular characterisation of lineage IV peste des petits ruminants virus using multi gene sequence data. Vet. Microbiol. 174: 39-49.

Libeau, G., Diallo, A., Colas, F., and Guerre, L. 1994. Rapid differential diagnosis of rinderpest and peste des petits ruminants using an immunocapture ELISA. Vet Rec. 134: 300-4.

Nanda, S.K., and Baron, M.D. 2006. Rinderpest virus blocks type I and type II interferon action: role of structural and nonstructural proteins. J Virol. 80:7555-68.

Nanda, Y.P., Chatterjee, A., Purohit, A.K., Diallo, A., Innui, K., Sharma, K.N., Libeau, G., Thevasagayam, J.A., Bruning, A., Kitching, R.P., Anderson, 
J., Barrett, T., and Taylor, W.P. 1996. The isolation of peste des petits ruminants virus from Northern India. Vet. Microbiol. 51(3-4): 207-216.

Parida, S., Muniraju, M., Mahapatra, M., Muthuchelvan, D., Buczkowski, H., and Banyard, A. C. 2015. Peste des petits ruminants. Veterinary Microbiology, 181: 90-106.

Parida, S., Selvaraj, M., Gubbins, S., Pope, R., Banyard, A., and Mahapatra, M. 2019. Quantifying Levels of Peste Des Petits Ruminants (PPR) Virus in Excretions from Experimentally Infected Goats and Its Importance for Nascent PPR Eradication Programme. Viruses11: 249.

Raghavendra, A.G., Gajendragad, M.R., Sengupta, P.P., Patil, S.S., Tiwari, C.B., Balumahendiran, M., Sankri, V., and Prabhudas, K. 2008. Seroepidemiology of peste des petits ruminants in sheep and goats of southern peninsular India. Rev. - Off. Int. Epizoot. 27: 861-867.

Sen, A., Saravanan P., Balamurugan, V.,Bhanuprakash, V.,Venkatesan, G., Sarkar, J., Rajak K. K., Ahuja A.,
Yadav V., Sudhakar S. B., Parida S. R. K. Singh. 2014. Detection of subclinical peste des petits ruminants virus

Singh, R.P., Sreenivasa, B.P., Dhar, P., Shah, L.C., and Bandyopadhyay, S.K. 2004. Development of a monoclonal antibody based competitive-ELISA for detection and titration of antibodies to peste des petits ruminants (PPR) virus. Vet Microbiol. 98: 3-15.

Toplu, N., Oguzoglu, T.C., and Albayrak, H. 2012. Dual infection of fetal and neonatal small ruminants with border disease virus and peste des petits ruminants virus (PPRV): neuronal tropism of PPRV as a novel finding. J Comp Pathol. 146:289-97.

Truong, T., Boshra, H., Embuoy- Hyatt, C., Nfon, C., Gerdts, V., Tikoo, S., Babiuk, L.A., Kara, P., Chetty, T., Mather, A., Wallace D.B., and Babiue, S. 2014. Peste des petits ruminants virus tissue Tropism and pathogenesis in sheep and goat following experimental infection PLoS ONE, 9: e87145.

\section{How to cite this article:}

Pragati Bhoyar, Prabhakar Tembhurne, Ruchi Bhate, Prashant Tarale, Anuradha Nemade Anand Kadam, Jivan Kesharkar and Ingle, V.C. 2019. Molecular Detection of Peste des-petits ruminant virus (PPRV) by RT-PCR. Int.J.Curr.Microbiol.App.Sci. 8(11): 2594-2601. doi: https://doi.org/10.20546/ijcmas.2019.811.300 